\title{
Outcrossing and paternity analysis of Pinus densiflora (Japanese red pine) by microsatellite polymorphism
}

\author{
CHUNLAN LIAN*, MAKOTO MIWA ${ }^{1} \&$ TAIZO HOGETSU \\ Asian Natural Environmental Science Center, The University of Tokyo, Midori-cho 1-1-8, Nishi Tokyo, \\ Tokyo 188-0002, Japan
}

\begin{abstract}
This study employed microsatellite loci to analyse outcrossing rate and pollen dispersal in Japanese red pine (Pinus densiflora) in an isolated stand. The average offspring outcrossing rate for 29 cones was 0.955 . Significant differences in outcrossing rates between offspring groups on individual branches that extended in different directions at different heights were not detected. Male parents of 874 offspring collected from the maternal tree were assessed by exclusion using polymorphisms at three microsatellite loci. Paternity analysis indicated that at least $31 \%$ of the offspring were fertilized by pollen from trees outside the stand. The average distance of pollen migration within the study stand was $68 \mathrm{~m}$, with a maximum value of $325 \mathrm{~m}$. There was excess mating with nearby $P$. densiflora trees, of which only a few were predominant pollen donors. In addition, a weakly directional bias in $P$. densiflora pollination was also detected in the study stand, suggesting that female strobili on a branch of the maternal tree were more easily fertilized by pollen from trees in that direction.
\end{abstract}

Keywords: microsatellite, outcrossing rate, paternity analysis, Pinus densiflora, pollen dispersal.

\section{Introduction}

Japanese red pine (Pinus densiflora Sieb. \& Zucc.) is one of the most widely distributed Japanese conifers. This species grows naturally on a wide variety of sites, extending from the foot of Mt. Tarumai in Hokkaido $\left(30^{\circ} 15^{\prime} \mathrm{N}\right)$, the northernmost island in Japan, to the southern part of Yaku Island $\left(42^{\circ} 40^{\prime} \mathrm{N}\right)$, and from sea level to an altitude of $2290 \mathrm{~m}$ (Hayashi, 1952). Extensive mortality, resulting from damage caused by pinewood nematodes (Bursaphelenchus xylophilus), has gradually increased in southwestern Japan since the 1940s. Knowledge of the mating processes and patterns of natural effective pollen movement may be indispensable for successful pine forest protection and regeneration, although these have not yet been reported in Japanese red pine.

Patterns of mating and gene flow via pollen dispersal within populations strongly affect genetic variation and the rate and direction of microevolutionary change (Schuster \& Mitton, 2000). However, pollen dispersal based on measuring physical pollen movements using traps (Greenwood, 1986) or dyes (Linhart et al., 1987;

*Correspondence. E-mail: lian@uf.a.u-tokyo.ac.jp

${ }^{1}$ Present address: Center for Environmental Science in Saitama, Kamitanadare 914, Kisai Town, Kita-saitama-gun, Saitama-3470115, Japan.
Campbell, 1991) may not always reflect actual fertilization and gene flow among local populations (for review, see Dow \& Ashley, 1998a, b; Streiff et al., 1999).

Recently, approaches using molecular markers have been used to estimate effective gene flow by comparing the segregation of genetic markers in the parental and offspring cohorts. In particular, there has been a rapid increase in studies using microsatellite markers to estimate mating patterns and pollen dispersal in natural tree populations (Dow \& Ashley, 1996; Dawson et al., 1997, 1998a; Dayanandan et al., 1999; Streiff et al., 1999; Isagi et al., 2000; Ueno et al., 2000). Such markers allow estimation of allele frequencies, and a high exclusion probability for paternity assignment, owing to their codominant inheritance and high polymorphism.

In this study, highly polymorphic microsatellite markers were used to estimate outcrossing rate and effective pollen donors for offspring produced on individual branches of a single Japanese red pine growing in an isolated stand.

\section{Materials and methods}

\section{Study site}

The study site was in the University of Tokyo's Experimental Station at Tanashi, located in suburban 
Tokyo. The Experimental Station occupies 9.12 ha and is surrounded by residential areas. Only a few scattered individual pines grow in parks and gardens around the experimental station. There was no prevailing wind from April to May 1998 during the flowering period of P. densiflora.

The experimental station contains two groups of Japanese red pine (Fig. 1). The first group consists of 101 trees that are about 70 years old and over $15 \mathrm{~m}$ high. These trees arose from natural regeneration and are scattered throughout the experimental station. The second group comprises 53 individuals about 20 years old and $10 \mathrm{~m}$ high, clustered in the northern part of the Experimental Station (Plot A, Fig. 1), that were planted from the seeds of trees growing in the experimental station. The positions of the 70-year-old trees were obtained from a survey distributed by the station; those of the 20-year-old trees in Plot A were measured using a survey laser instrument (Criterion 300, Laser Technology, Englewood, Co., USA).

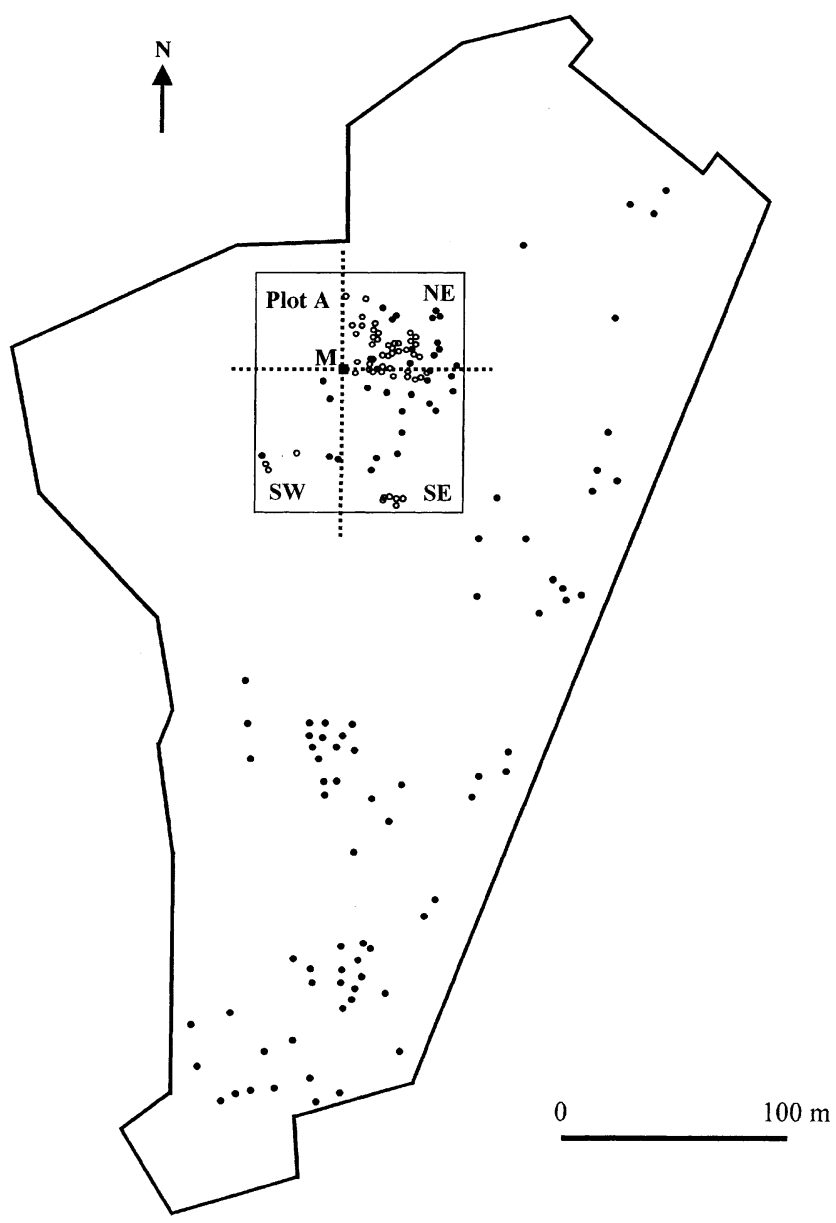

Fig. 1 Map of the Pinus densiflora study stand. Closed and open circles represent trees that were approximately 70 and 20 -year-old, respectively. $\mathrm{M}$ is the maternal tree.

\section{Sample collection and preparation}

For the outcrossing and paternity analysis, a maternal tree of $26 \mathrm{~cm}$ d.b.h. (diameter at breast height) and $12 \mathrm{~m}$ height, branching above $3 \mathrm{~m}$, located to the west of most of the trees in Plot A was chosen (Fig. 1). In October 1999, two or three apparently undamaged mature cones were collected from branches that extended in different directions at different heights on the maternal tree (Table 1). Seeds were collected from each cone and stored at $4{ }^{\circ} \mathrm{C}$ for 40 days. In order to facilitate germination, seeds were soaked in distilled water at $4^{\circ} \mathrm{C}$ overnight and then sown in individual pots containing an autoclaved $\left(120^{\circ} \mathrm{C}, 2 \mathrm{~h}\right)$ mixture $(1: 1 \mathrm{v} / \mathrm{v})$ of Tanashi nursery soil (black sand loam) and Shibanome soil (volcanic sand) in a greenhouse $\left(25^{\circ} \mathrm{C}\right.$ day: $23^{\circ} \mathrm{C}$ night). After 30 days, all the needles were removed from each seedling and DNA was immediately extracted. If more than 34 seedlings were available from a cone, then 34 seedlings were randomly chosen for analysis. Fresh needles were also collected from all 154 adult trees in the experimental station.

\section{DNA extraction and microsatellite analysis}

Crude genomic DNA was extracted from fresh $P$. densiflora needles using a modified CTAB method. About $100 \mathrm{mg}$ material was homogenized for at least $45 \mathrm{~s}$ in $700 \mu \mathrm{L} 2 \times \mathrm{CTAB}$ solution using a FastPrep ${ }^{\mathrm{TM}}$ FP120 machine (Savant, USA), and incubated at $65^{\circ} \mathrm{C}$ for $1 \mathrm{~h}$. DNA was isolated using chloroform-isoamyl alcohol (24:1) extraction, precipitation in isopropanol,

Table 1 Direction and height of branches, and numbers of total and sampled cones on each Pinus densiflora branch

\begin{tabular}{lccc}
\hline $\begin{array}{l}\text { Branch } \\
\text { direction }\end{array}$ & $\begin{array}{c}\text { Branch } \\
\text { height (m) }\end{array}$ & $\begin{array}{c}\text { Total no. } \\
\text { cones on } \\
\text { each branch }\end{array}$ & $\begin{array}{c}\text { No. cones } \\
\text { sampled }\end{array}$ \\
\hline South & & & \\
$\quad$ S1 & 9.1 & 27 & 3 \\
S2 & 6.0 & 14 & 2 \\
S3 & 4.6 & 3 & 2 \\
North-east & & & 3 \\
NE1 & 9.6 & 2 & 3 \\
NE2 & 8.9 & 13 & 3 \\
NE3 & 6.2 & 5 & 3 \\
North-west & & & 4 \\
NW1 & 10.8 & 4 & 3 \\
NW2 & 9.4 & 7 & \\
$\quad$ NW3 & 6.4 & 16 & \\
South-west & 5.5 & 8 & \\
\hline
\end{tabular}


and washing in $75 \%$ ethanol. Extracted DNA was dissolved in $100 \mu \mathrm{L}$ Tris-EDTA (TE) buffer. For paternity analysis, four microsatellite PCR primer pairs (Pde3, Pde5, Pde7, Pde14), developed by Lian et al. (2000), were used to score genotypes. The PCR reaction conditions were the same as those described previously (Lian et al., 2000). The reaction products were electrophoresed on a $6 \%$ Long Ranger sequencing gel (FMC BioProducts Co., ME, USA) using a SQ-5500 sequencer (Hitachi Co., Tokyo). Electrophoretic patterns were analysed with FRAGLYS v. 2 software (Hitachi Electronics Engineering Co., Tokyo).

\section{Data analysis}

For each locus, allele frequencies were determined, and Nei's (1987) method was employed to calculate expected heterozygosity $\left(H_{\mathrm{E}}\right)$. Differences in allele frequency distribution between adults and the offspring produced on individual branches of the maternal tree were tested using the Kolmogorov-Smirnov test (Morin et al., 1994). The multilocus outcrossing rate $\left(t_{\mathrm{m}}\right)$ was estimated using a maximum likelihood method (Shaw et al., 1981). Paternity was assessed by simple exclusion, based on multilocus genotypes (Dow \& Ashley, 1996; Schnabel, 1998; Streiff et al., 1999). Possible paternal alleles at every locus, inferred by subtracting the maternal alleles from offspring alleles, were compared with those of adult trees; adults that did not share the possible paternal alleles at least at one locus were excluded as not being possible male parents of the offspring.

The correlations between fertilization frequency of offspring in the maternal tree by pollen from an individual paternal tree and distance of the paternal tree from the maternal tree were statistically analysed. The paternal trees were classified according to their distance from the maternal tree at $10-\mathrm{m}$ intervals. The average frequency of offspring fertilized by paternal trees that were included in each distance class, was plotted against distances from the maternal tree. The correlation was estimated using a negative exponential model.

In order to investigate fertilization bias caused by the directions of paternal trees to the mother tree, the surrounding area of the maternal tree was divided into four quadrants, northeastern (NE), southeastern (SE), southwestern (SW), and northwestern (NW) quadrants, as shown in Fig. 1. The frequency of offspring fertilized by paternal trees in each quadrant were calculated for offspring in cones on branches which were extended in each direction. The frequency distribution of paternity of trees in the four quadrants was compared between branches extending in different directions.

\section{Results}

\section{Allele frequency}

No alleles at locus Pde7 of the maternal tree were amplified in $50 \%$ of the progeny, indicating there was a common null allele at this locus. Thus, locus Pde7 was excluded from further analysis.

The total number of alleles per locus ranged from 24 to 37 in adult trees and from 7 to 24 in offspring produced on individual branches of the maternal tree (Table 2). At all loci, several alleles appearing in the offspring genotypes were absent from the adults. The heterozygosities of individual loci ranged from 0.762 to 0.915 in adult trees and from 0.602 to 0.936 in the offspring produced on individual branches of the maternal tree (Table 2).

The differences in allele frequency distribution between each offspring group sampled from individual branches and adult trees and between the offspring groups were tested using the Kolmogorov-Smirnov test. The allele frequencies at loci Pde5 and Pde14 in adult trees were significantly different from those in every offspring group $(P<0.05)$. Although the allele frequencies at locus Pde3 in most offspring groups were significantly different from those in adult trees $(P<0.05)$, groups $\mathrm{S} 1$ and NW2 did not show different allele frequencies from adult trees. No significant differences among offspring groups were found at any locus.

\section{Outcrossing rate}

Outcrossing rates for offspring from individual cones varied from 0.777 to over 1 (mean 0.955); of the 29 cones investigated, the offspring outcrossing rates in 11 cones $(38 \%)$ were over 1 (Fig. 2). F-statistics did not show significant differences among the outcrossing rates of offspring on different branches of the maternal tree, except for those in the northwestern group (Table 3). On northwestern branches of the maternal tree, the outcrossing rate of offspring from the upper cones (NW1) was significantly higher than that from the middle (NW2) and lower (NW3) cones $(P<0.05)$.

The germination frequency of seeds from individual cones ranged from 56.3 to $85.3 \%$, and there was a significant positive correlation between germination frequency and outcrossing rate $(r=0.407$, d.f. $=29$, $P<0.05$; Fig. 3).

\section{Paternity analysis}

By simple exclusion analysis, at least 38 of the 154 adult trees within the study stand did not fertilize any offspring in the maternal tree. Twelve of these 38 trees grow in Plot

(C) The Genetics Society of Great Britain, Heredity, 87, 88-98. 
Table 2 Allele frequencies, numbers, and expected heterozygosities at three microsatellite loci of 154 adult Pinus densiflora trees and offspring produced on individual branches of the maternal tree. $A$ and $H_{\mathrm{E}}$ represent the number of alleles and expected heterozygosities, respectively

\begin{tabular}{|c|c|c|c|c|c|c|c|c|c|c|c|}
\hline \multirow[b]{2}{*}{ Allele } & \multicolumn{11}{|c|}{ Frequency } \\
\hline & Adult & S1 & S2 & S3 & NE1 & NE2 & NE3 & NW1 & NW2 & NW3 & SW \\
\hline \multicolumn{12}{|c|}{ Locus Pde3 } \\
\hline 152 & 0.004 & 0.010 & 0 & 0 & 0 & 0 & 0 & 0 & 0 & 0.011 & 0.012 \\
\hline 174 & 0.004 & 0 & 0 & 0 & 0 & 0 & 0 & 0 & 0 & 0 & 0 \\
\hline 176 & 0.127 & 0.115 & 0.110 & 0.157 & 0.088 & 0.114 & 0.106 & 0.063 & 0.070 & 0.067 & 0.085 \\
\hline 178 & 0.014 & 0.010 & 0 & 0 & 0 & 0 & 0 & 0 & 0 & 0 & 0 \\
\hline 180 & 0.032 & 0.042 & 0.082 & 0.039 & 0.070 & 0.034 & 0.165 & 0.089 & 0.081 & 0.337 & 0.085 \\
\hline 182 & 0.004 & 0.042 & 0.014 & 0 & 0 & 0.045 & 0.024 & 0 & 0.023 & 0 & 0.012 \\
\hline 193 & 0.444 & 0.438 & 0.521 & 0.608 & 0.491 & 0.420 & 0.400 & 0.468 & 0.453 & 0.449 & 0.451 \\
\hline 197 & 0.063 & 0.031 & 0 & 0 & 0.035 & 0.023 & 0.035 & 0.051 & 0.035 & 0.034 & 0.061 \\
\hline 198 & 0.011 & 0.010 & 0 & 0 & 0.018 & 0 & 0.012 & 0.025 & 0.035 & 0 & 0.012 \\
\hline 199 & 0 & 0.021 & 0 & 0 & 0 & 0 & 0 & 0 & 0.012 & 0 & 0 \\
\hline 203 & 0.011 & 0 & 0.014 & 0 & 0 & 0.011 & 0.024 & 0 & 0.012 & 0 & 0 \\
\hline 205 & 0.127 & 0.146 & 0.110 & 0.098 & 0.053 & 0.125 & 0.071 & 0.165 & 0.081 & 0.056 & 0.085 \\
\hline 207 & 0.014 & 0.052 & 0.041 & 0.059 & 0.070 & 0.091 & 0.071 & 0.038 & 0.035 & 0.022 & 0.061 \\
\hline 208 & 0.007 & 0 & 0 & 0 & 0.018 & 0.011 & 0 & 0 & 0 & 0 & 0 \\
\hline 209 & 0.014 & 0.010 & 0.041 & 0.020 & 0.018 & 0.023 & 0.012 & 0.025 & 0.058 & 0 & 0.073 \\
\hline 212 & 0.004 & 0 & 0 & 0 & 0 & 0 & 0 & 0 & 0 & 0 & 0 \\
\hline 225 & 0.004 & 0 & 0 & 0 & 0 & 0 & 0 & 0 & 0 & 0 & 0 \\
\hline 227 & 0.014 & 0 & 0 & 0 & 0 & 0 & 0.012 & 0 & 0 & 0.011 & 0 \\
\hline 229 & 0.004 & 0 & 0 & 0 & 0 & 0 & 0 & 0 & 0 & 0 & 0 \\
\hline 230 & 0.018 & 0.010 & 0 & 0 & 0 & 0 & 0 & 0.013 & 0.012 & 0 & 0 \\
\hline 233 & 0 & 0 & 0 & 0 & 0 & 0 & 0 & 0.013 & 0 & 0 & 0 \\
\hline 243 & 0.021 & 0.010 & 0.014 & 0 & 0.053 & 0.023 & 0.012 & 0 & 0.012 & 0 & 0.037 \\
\hline 245 & 0.004 & 0 & 0 & 0 & 0 & 0 & 0 & 0 & 0 & 0 & 0 \\
\hline 248 & 0 & 0 & 0 & 0 & 0.018 & 0 & 0 & 0.013 & 0.012 & 0 & 0 \\
\hline 253 & 0 & 0 & 0 & 0 & 0 & 0 & 0.012 & 0 & 0 & 0 & 0 \\
\hline 256 & 0 & 0 & 0 & 0.020 & 0 & 0 & 0 & 0 & 0 & 0 & 0 \\
\hline 259 & 0.046 & 0.052 & 0.041 & 0 & 0.070 & 0.080 & 0.047 & 0.025 & 0.058 & 0.011 & 0.024 \\
\hline 261 & 0.011 & 0 & 0.014 & 0 & 0 & 0 & 0 & 0.013 & 0.012 & 0 & 0 \\
\hline 268 & 0.004 & 0 & 0 & 0 & 0 & 0 & 0 & 0 & 0 & 0 & 0 \\
\hline$A$ & 24 & 15 & 11 & 7 & 12 & 12 & 14 & 13 & 16 & 9 & 12 \\
\hline$H_{\mathrm{E}}$ & 0.762 & 0.771 & 0.702 & 0.602 & 0.741 & 0.784 & 0.796 & 0.745 & 0.773 & 0.682 & 0.769 \\
\hline \multicolumn{12}{|c|}{ Locus Pde5 } \\
\hline 116 & 0.181 & 0.125 & 0.123 & 0.098 & 0.140 & 0.170 & 0.082 & 0.190 & 0.198 & 0.101 & 0.110 \\
\hline 118 & 0.142 & 0.094 & 0.151 & 0.157 & 0.140 & 0.182 & 0.165 & 0.127 & 0.081 & 0.011 & 0.073 \\
\hline 122 & 0.004 & 0 & 0 & 0 & 0 & 0 & 0 & 0 & 0 & 0 & 0 \\
\hline 124 & 0.117 & 0.094 & 0.137 & 0.167 & 0.070 & 0.136 & 0.041 & 0.051 & 0.087 & 0.006 & 0.079 \\
\hline 126 & 0.043 & 0.021 & 0.041 & 0 & 0.018 & 0.023 & 0.024 & 0.038 & 0.012 & 0.011 & 0.024 \\
\hline 128 & 0.004 & 0.021 & 0.014 & 0 & 0.035 & 0.068 & 0.024 & 0.013 & 0.047 & 0.011 & 0.012 \\
\hline 130 & 0.007 & 0 & 0 & 0 & 0 & 0 & 0 & 0 & 0 & 0 & 0 \\
\hline 176 & 0 & 0 & 0.014 & 0 & 0 & 0 & 0 & 0 & 0 & 0.011 & 0 \\
\hline 178 & 0.011 & 0.052 & 0.041 & 0.020 & 0.053 & 0.011 & 0.012 & 0.013 & 0.035 & 0 & 0.037 \\
\hline 186 & 0.082 & 0.135 & 0.068 & 0.078 & 0.123 & 0.068 & 0.094 & 0.063 & 0.128 & 0.011 & 0.098 \\
\hline 189 & 0.007 & 0 & 0 & 0 & 0 & 0.011 & 0 & 0 & 0 & 0 & 0 \\
\hline 190 & 0.007 & 0.010 & 0.014 & 0 & 0.018 & 0 & 0 & 0.013 & 0 & 0 & 0 \\
\hline 191 & 0.004 & 0 & 0.014 & 0.020 & 0 & 0 & 0 & 0 & 0 & 0 & 0.012 \\
\hline 194 & 0.028 & 0.031 & 0.041 & 0.020 & 0.018 & 0 & 0.047 & 0.013 & 0.012 & 0.034 & 0.049 \\
\hline 195 & 0.004 & 0 & 0 & 0 & 0 & 0 & 0 & 0 & 0 & 0 & 0 \\
\hline 196 & 0.014 & 0.010 & 0.014 & 0 & 0 & 0 & 0 & 0 & 0.035 & 0 & 0.012 \\
\hline 199 & 0.007 & 0.010 & 0 & 0 & 0 & 0 & 0 & 0.013 & 0 & 0 & 0.012 \\
\hline
\end{tabular}

(C) The Genetics Society of Great Britain, Heredity, 87, 88-98. 
Table 2 (Continued)

Frequency

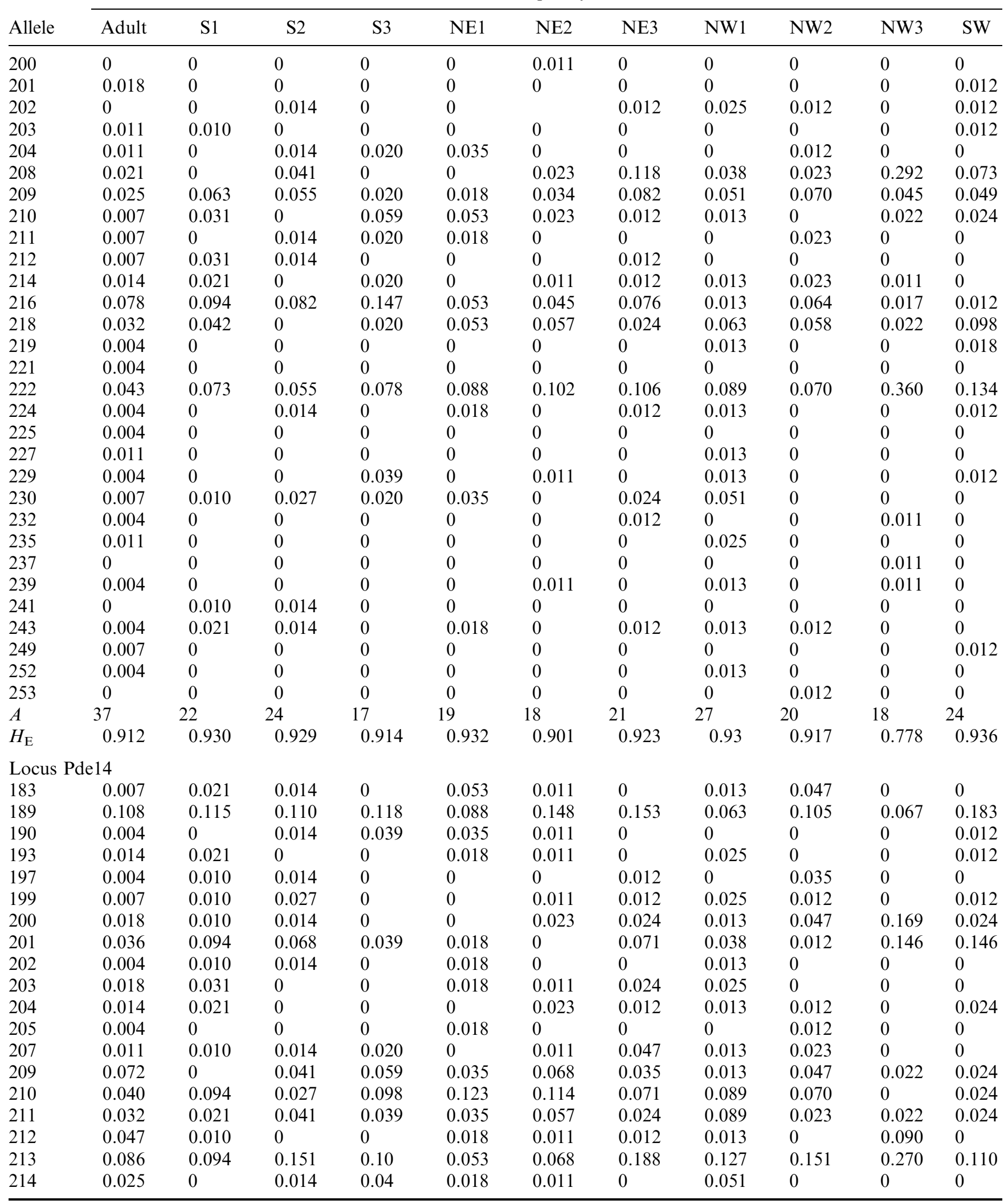


Table 2 (Continued)

\begin{tabular}{|c|c|c|c|c|c|c|c|c|c|c|c|}
\hline Allele & \multicolumn{11}{|c|}{ Frequency } \\
\hline 216 & 0.018 & 0 & 0 & 0 & 0.018 & 0.023 & 0 & 0 & 0 & 0 & 0 \\
\hline 217 & 0.076 & 0.031 & 0.055 & 0.039 & 0 & 0.068 & 0.047 & 0.051 & 0.058 & 0.067 & 0.037 \\
\hline 218 & 0.029 & 0.042 & 0.027 & 0.059 & 0.018 & 0.045 & 0.035 & 0.051 & 0.105 & 0.034 & 0.085 \\
\hline 224 & 0.004 & 0.010 & 0 & 0 & 0 & 0 & 0.012 & 0 & 0 & 0 & 0 \\
\hline 226 & 0 & 0 & 0 & 0.020 & 0 & 0.011 & 0 & 0 & 0 & 0 & 0.012 \\
\hline 229 & 0.004 & 0 & 0 & 0 & 0 & 0 & 0 & 0 & 0 & 0 & 0 \\
\hline 231 & 0.014 & 0 & 0 & 0 & 0 & 0.011 & 0.012 & 0.025 & 0.023 & 0.011 & 0.024 \\
\hline 232 & 0 & 0.010 & 0.014 & 0 & 0.018 & 0.011 & 0.012 & 0.013 & 0 & 0 & 0.012 \\
\hline$A$ & 31 & 21 & 19 & 16 & 20 & 23 & 21 & 23 & 18 & 12 & 18 \\
\hline$H_{\mathrm{E}}$ & 0.915 & 0.908 & 0.904 & 0.930 & 0.906 & 0.916 & 0.910 & 0.934 & 0.922 & 0.862 & 0.900 \\
\hline
\end{tabular}

Frequencies of offspring alleles include only the paternal contribution to the genotype.

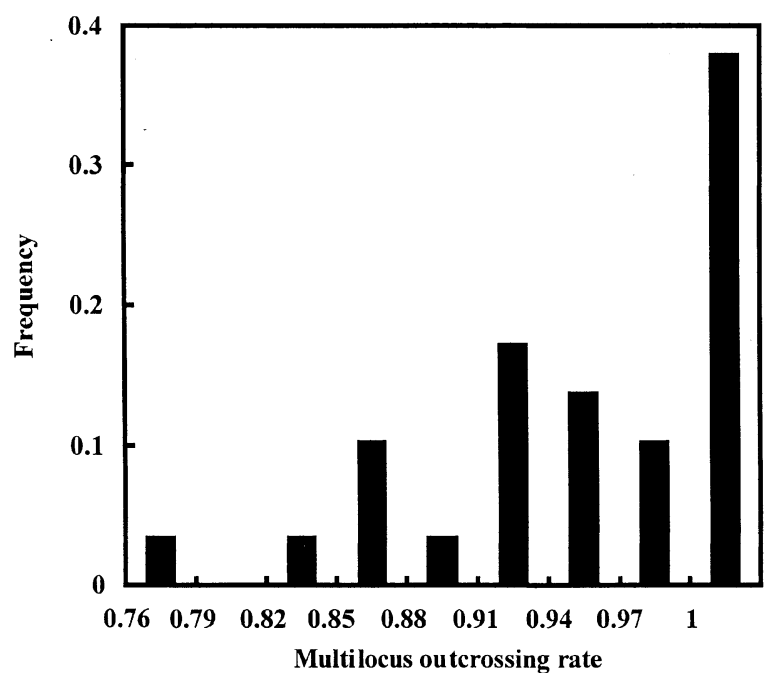

Fig. 2 Frequency distribution of multilocus outcrossing rates among offspring sampled from individual Pinus densiflora cones. Cones were grouped according to multilocus outcrossing rates of offspring within them at 0.03 intervals.

A, which contains 83 adult trees. For 604 out of the 874 offspring analysed, possible male parents were identified as adult trees within the study stand. Of these 604 offspring, 403 had a single possible male parent and 201 had two or more possible male parents. Simple exclusion analysis indicated that 56 were produced by self-fertilization. In contrast, 270 offspring had no compatible male parents within the study stand. Therefore, their male parents were outside the study stand.
Table 3 Multilocus outcrossing rates (SD) of offspring produced from individual cones on different branches of Pinus densiflora. Numbers in parentheses are standard deviations

\begin{tabular}{ll}
\hline Branch position & Multilocus outcrossing rate \\
\hline South & $0.975(0.096)$ \\
S1 & $0.946(0.023)$ \\
S3 & $0.932(0.048)$ \\
S3 & $0.954(0.063)$ \\
Average & \\
North-east & $0.949(0.039)$ \\
NE1 & $0.886(0.122)$ \\
NE2 & $0.965(0.049)$ \\
NE3 & $0.931(0.081)$ \\
Average & \\
North-west & $1.017(0.005)^{* * *}$ \\
NW1 & $0.931(0.077)$ \\
NW2 & $0.926(0.075)$ \\
NW3 & $0.958(0.070)$ \\
Average & $0.971(0.053)$ \\
South-west &
\end{tabular}

$* * P<0.05$.

The pollen migration distances for the 347 outcrossing offspring for which single male parents were identified within the Experimental Station, ranged from 6 to $325 \mathrm{~m}$, with an average of $68 \pm 72 \mathrm{~m}$ (SD) (Fig. 4). There was a significant negative correlation between the 


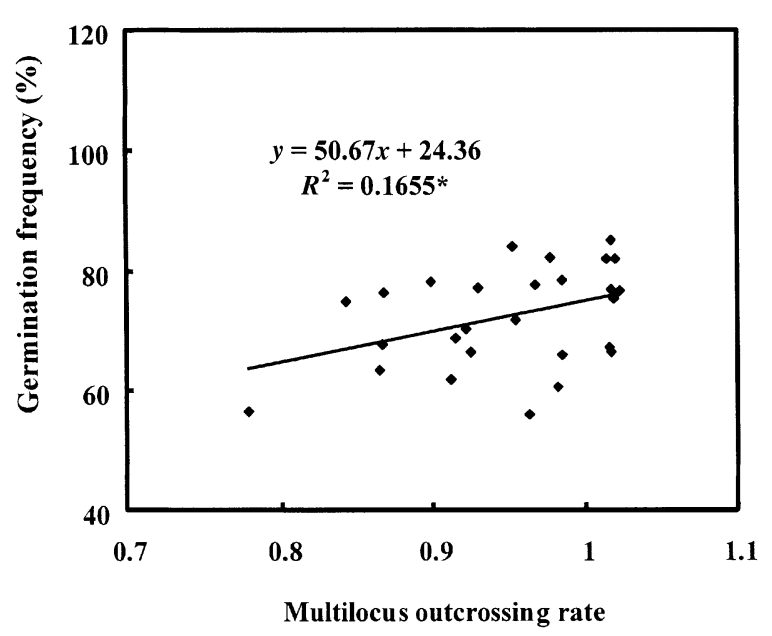

Fig. 3 Correlation between germination frequency and multilocus outcrossing rate of offspring sampled from individual Pinus densiflora cones. The asterisk (*) indicates that the coefficient was significant at $P<0.05$.

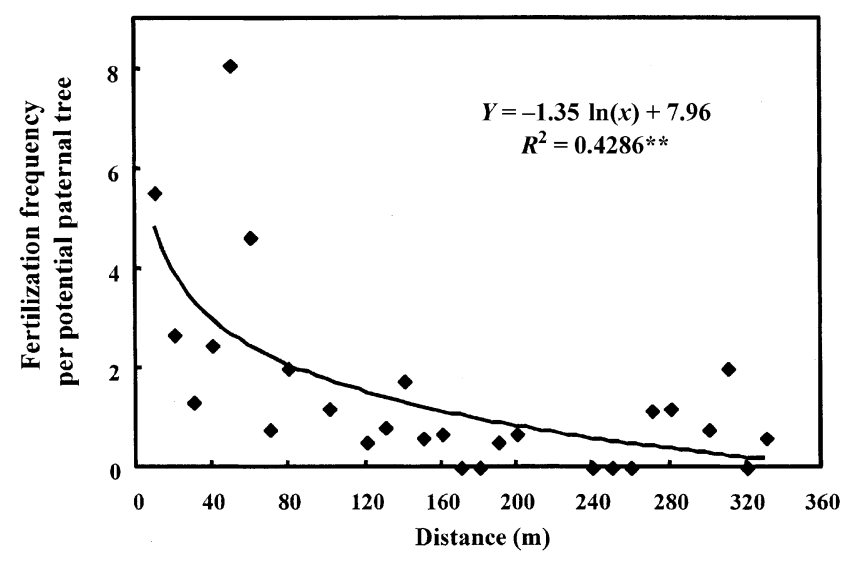

Fig. 4 Correlation between offspring fertilization frequency in the maternal Pinus densiflora tree by pollen from given paternal trees and distance between the parents. Double asterisks $(* *)$ indicate that the coefficient was significant at $P<0.01$.

number of offspring fertilized by an individual tree and the distance between the paternal and maternal trees in the study stand.

The distribution of paternal trees that fertilized offspring produced on individual branches of the maternal tree was significantly biased according to branch direction $\left(P<0.05, \chi^{2}\right.$ test) (Figs 5 and 6 ). Offspring produced on southern branches of the maternal tree were fertilized relatively more often by pollen from adult trees south-east and north-east of the maternal tree. Offspring on the northeastern and northwestern branches were fertilized relatively more often by pollen from trees to the north-east. Pollen donors for offspring produced on the south-western branches of the maternal tree were mostly to the south-east. There was a conspicuous tendency for pollen from a small number of trees to fertilize the offspring, i.e. eight out of 154 individuals fertilized $42 \%$ of the offspring of the maternal tree. Trees 2 and 33 fertilized 9.8 and $9.2 \%$ of the total offspring, respectively (Fig. 5). Tree 33, which was north-east of the maternal tree, fertilized $20 \%$ of the offspring on the northeastern branches, $10 \%$ on the southern branches, $5.1 \%$ on the northwestern branches, and $4.2 \%$ on the southwestern branches.

Within the study stand, no trees were located to the north-west of the maternal tree. The fertilization frequency of offspring on branches of the maternal tree pointing in different directions by pollen from outside the stand varied. The highest levels of fertilization by pollen from outside trees were detected in offspring produced on the southwestern and northwestern branches and were $38 \%$ and $36 \%$, respectively. The lowest rate, $24 \%$, occurred on the southern branches.

\section{Discussion}

\section{Outcrossing rate of $\mathrm{P}$. densiflora}

The multilocus outcrossing rate of $P$. densiflora estimated in this study stand averaged 0.955 , and was similar to that of other pine species: 0.862 for P. washoensis (Mitton et al., 1997), 0.987 for P. sylvestris (Burczyk, 1998), and 0.944 for P. ponderosa (Sorensen, 1994). This value is higher than that of most broad-leafed species, such as Helicteres brevispira $\left(t_{\mathrm{m}}=0.478-0.676\right)$ (France schinelli \& Bawa, 2000), Eucalyptus rhodantha $\left(t_{\mathrm{m}}=0.59-0.65\right)$, and Cavanillesia platanifolia $\left(t_{\mathrm{m}}=0.213-0.569\right)$ (Murawski, 1995). Mitton (1992) suggested that conifers generally produce seeds by outcrossing, and the high outcrossing rate of $P$. densiflora is consistent with this hypothesis.

In this study, the offspring outcrossing rate from each cone produced on individual branches of the maternal tree did not depend on branch position, i.e. the height or direction of the branch bearing the cone, and varied considerably among cones from 0.77 to over 1.00 . From 11 out of 29 cones, all offspring were produced by outcrossing. Although no comparison between cones of offspring outcrossing rates on an individual pine has previously been reported, investigators have reported dependence and independence of the outcrossing rate on the height of branches or position of trees within a population. Franklin (1971) reported that the outcrossing rate in $P$. taeda seeds depended on sampling height. Shaw \& Allard (1982) also reported a similar dependence on tree position within Douglas-fir populations 

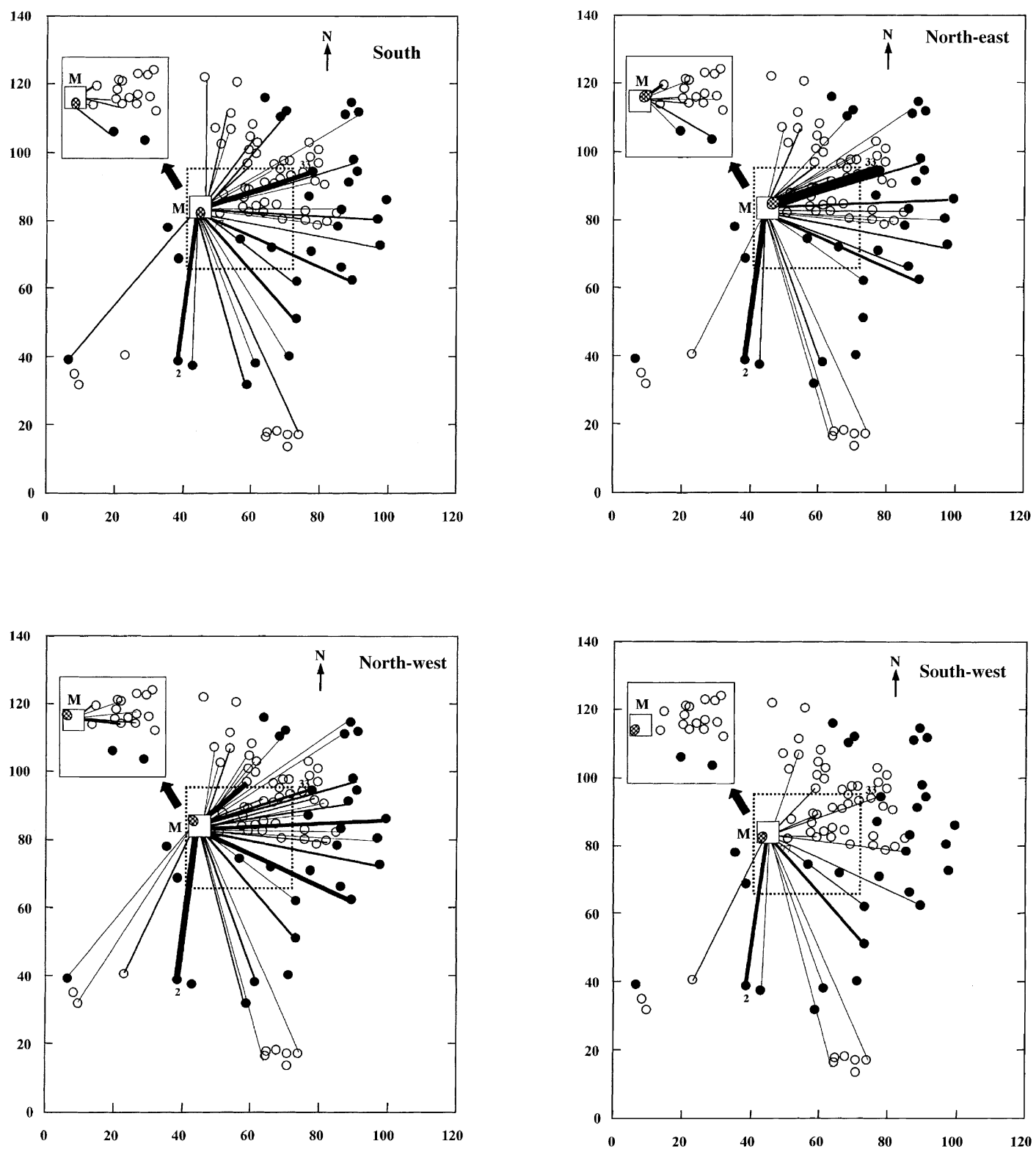

Fig. 5 Location of pollen donors within Plot A for offspring produced on branches of maternal Pinus densiflora tree that extended to south-west, south, north-east, and north-west., , c. 70-year-old trees; $\bigcirc, c$. 20-year-old trees. Line width connecting a tree with the maternal tree represents the number of offspring that were inferred to be fertilized by pollen from that individual.

The narrowest and broadest lines represent 1 and 17 offspring, respectively.

along roadsides or the edges of natural breaks. On the contrary, almost no dependence of the outcrossing rate on tree position was observed in a young Douglas-fir grafted orchard (Shaw \& Allard, 1982), a low-density $P$. banksiana stand with trees of various heights (Cheliak et al., 1985), or an even-aged, natural $P$. contorta stand (Perry \& Dancik, 1986). Comparing the growth forms of $P$. contorta and $P$. ponderosa, Sorensen (1994) suggested that denser branching of $P$. contorta than $P$. ponderosa corresponds to its lower outcrossing rate. The maternal $P$. densiflora tree in our study was about 20 years old and sparsely branched. This shape might have permitted pollen from surrounding $P$. densiflora trees free access to its female strobili, resulting in the high outcrossing rate, as well as eliminating the effect of branch position on the outcrossing rate.

There was a significant positive correlation between germination frequency and outcrossing rate, from the correlation formula, under complete outcrossing and selfing, germination frequencies of $P$. densiflora seeds are estimated as $75.0 \%$ and $24.4 \%$, respectively. Using these two germination frequencies, we estimated the average

(C) The Genetics Society of Great Britain, Heredity, 87, 88-98. 


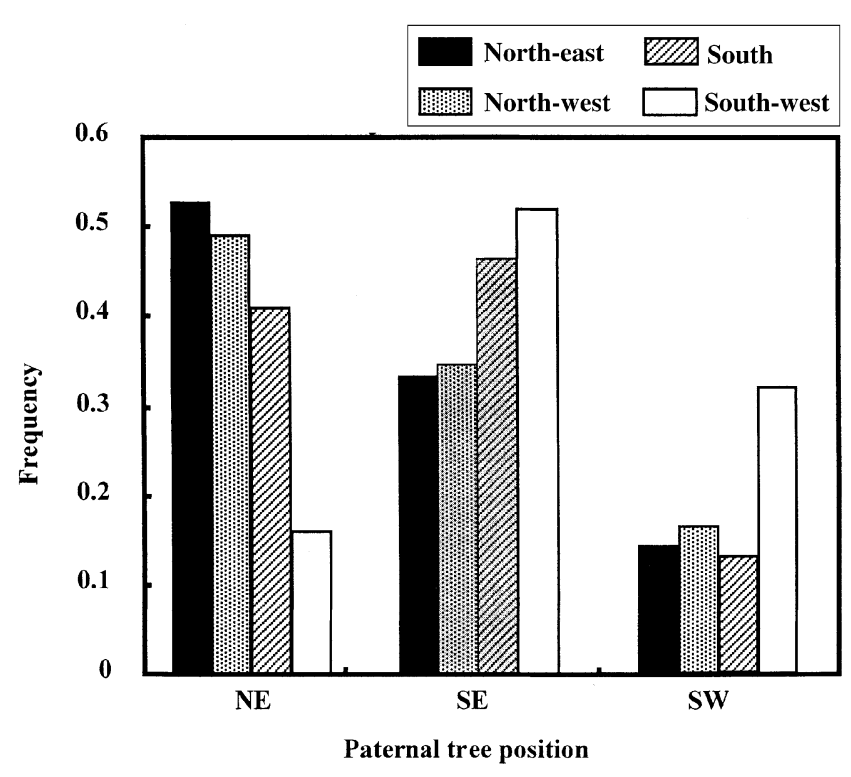

Fig. 6 Frequency distribution of offspring fertilized by paternal trees in three quadrants, i.e. north-east (NE), south-east (SE) and south-west (SW) within offspring from seeds borne on the maternal Pinus densiflora tree branches that extend south-west, south, north-east or north-west. The surrounding area of the maternal tree was divided into four quadrants: northeastern (NE), southeastern (SE), southwestern (SW), and northwestern (NW). There were no trees in NW quadrant. The frequency distribution of paternity of offspring from each directional group of branches was plotted against the three quadrants.

outcrossing rate of seeds to be 0.874 . This indicates that the outcrossing rate $(0.955)$ estimated from the seedlings produced from seeds might be an overestimate. Inbreeding depressions of seed viability, germination and growth tend to be severe for conifers (Mitton et al., 1997), eliminating inbred individuals between the seed and adult life stages. Therefore, the above inferences also imply that selfed seeds in $P$. densiflora may be at a selective disadvantage relative to outcrossed seeds.

\section{Paternity analysis of offspring produced on individual branches in a P. densiflora tree}

Polymorphism analysis using codominant markers enables inference of the pollen dispersal pattern. The paternity exclusion analysis of $P$. densiflora indicated that pollen from trees outside the study stand produced $270(31 \%)$ of the 874 analysed offspring of the maternal tree. Based on the position of paternal trees within the study stand, the average distance of pollen migration within the study stand was $68 \mathrm{~m}$ with a maximum value of $325 \mathrm{~m}$ (Fig. 4). These results correspond to the longdistance pollen migration reported in P. flexilis (Schuster
\& Mitton, 2000), P. sylvestris (Harju \& Nikkanen, 1996), and Quercus macrocarpa (Dow \& Ashley, 1996), and confirm the previous suggestion that gene flow in conifers may occur across long distances (Levin \& Kerster, 1974; Schuster \& Mitton, 2000).

Fertilization of offspring of the maternal tree with pollen from a paternal tree seemed to be correlated with the distance between the trees. P. densiflora pollen is windborne, and pollen density may be greater nearer the paternal tree. A significant negative correlation was found between the fertilization frequency by pollen from a given tree and its distance from the maternal tree (Fig. 4). This suggests that pollen density around female strobili might be one of the determining factors of fertilization in $P$. densiflora. However, this finding is not in agreement with the results for P. flexilis (Schuster \& Mitton, 2000) and P. ponderosa (Latta et al., 1998), which do not show an excess of near-neighbour matings. Pollen scattering by wind is influenced greatly both by meteorological conditions and tree growth form. Therefore, the correlation between fertilization frequencies and the distance between the parent trees may be labile, and condition dependent.

A directional bias of fertilization on individual branches of the maternal $P$. densiflora tree by trees located in different directions was seen with the direction of branch extension (Fig. 5). Within the study stand, no trees were located north-west of the maternal tree. The northwestern and southwestern branches of the maternal tree had higher levels of outside pollination. Moreover, the potential paternal trees distributed north of the maternal tree contributed more pollen to the northern branches of the maternal tree (Fig. 5). Female strobili on a given side of the maternal tree might be pollinated more easily by adult trees on the same side of the maternal tree. These results further confirm that the pollen density around female strobili might be an important factor for fertilization in $P$. densiflora. To our knowledge, pollination bias according to branch direction has not yet been investigated. To date, most investigations on the direction bias of pollination have focused on the level of the whole tree (Dow \& Ashley, 1998a; Streiff et al., 1999). Streiff et al. (1999) indicated that although fertilization in seven of the 13 maternal trees investigated was directionally biased in a mixed oak stand of Quercus robur and $Q$. petraea, it was not biased in the other six maternal trees. Tauber (1977) pointed out that modelling pollen dispersal is complex because of numerous sources of variation, such as wind direction and velocity, meteorological conditions, and local disturbances. Therefore, the directional bias of fertilization found on individual branches of the maternal $P$. densiflora tree might also vary with conditions.

(C) The Genetics Society of Great Britain, Heredity, 87, 88-98. 
The pollen that fertilized most of the offspring of the maternal tree was derived from a relatively small number of paternal trees. Dow \& Ashley (1998a) reported a similar result, in that much of the pollen that effectively fertilized seeds of $Q$. macrocarpa came from a small number of trees. As discussed above, if pollen density around female strobili primarily determines the fertilization frequencies, this means that a small number of trees in the population produced much more pollen than other trees, or had a phenology compatible with the maternal tree.

In conclusion, $P$. densiflora seeds were produced mainly by outcrossing, although the offspring fertilization frequency by the pollen of an individual paternal tree was somewhat correlated with the distance and direction of the paternal tree from the female strobili. Paternity tended to be confined to a small portion of the trees surrounding the maternal tree. The characteristics of pollen dispersal in $P$. densiflora demonstrated in the present study might be common to every windborne species, e.g. other Pinus species.

\section{Acknowledgements}

This work was supported in part by a grant from PROBRAIN and Grants-in-Aid from the Ministry of Education, Science, Sports and Culture of Japan. We thank the staff of Experimental Station at Tanashi, the University of Tokyo, for providing the tree map reference and their help in sampling.

\section{References}

BURCZYK, J. 1998. Mating system variation in a Scots pine clonal seed orchard. Silvae Genet., 47, 155-158.

CAMPBELl, D. R. 1991. Comparing pollen dispersal and gene flow in a natural population. Evolution, 45, 1965-1968.

CHELIAK, W. M., DANCIK, B. P., MORGAN, K., YEH, F. C. H. AND STROBECK, C. 1985. Temporal variation of the mating system in a natural population of jack pine. Genetics, $\mathbf{1 0 9}$, 569-584.

DAWSON, I. R., WAUGH, R., SIMONS, A. J. AND POWELL, W. 1997. Simple sequence repeats provide a direct estimate of pollenmediated gene dispersal in the tropical tree Gliricidia sepium. Mol. Ecol., 6, 179-183.

DAYANANDAN, Y., DOLE, J., BAWA, K. AND KESSELI, R. 1999. Population structure delineated with microsatellite markers in fragmented populations of a tropical tree, Carapa guianensis (Meliaceae). Mol. Ecol., 8, 1585-1592.

DOW, B. D. AND ASHLEY, M. v. 1996. Microsatellite analysis of seed dispersal and parentage of saplings in bur oak, Quercus macrocarpa. Mol. Ecol., 5, 615-627.

DOW, B. D. AND ASHLEY, M. v. 1998a. High levels of gene flow in bur oak revealed by paternity analysis using microsatellites. J. Hered., 89, 62-70.
DOW, B. D. AND ASHLEY, M. v. 1998b. Factors influencing male mating success in bur oak, Quercus macrocarpa. New Forests, 15, 161-180.

FRANCESCHINELLI, E. V. AND BAWA, K. S. 2000. The effect of ecological factors on the mating system of a South American shrub species (Helicteres brevispira). Heredity, 84, 116-123.

FRANKLIN, E. C. 1971. Estimates of frequency of natural selfing and inbreeding coefficients in loblolly pine. Silvae Genet., 20 , 194-195.

GREENWOOD, M. S. 1986. Gene exchange in loblolly pine: the relation between pollination mechanism, female receptivity and pollen availability. Am. J. Bot., 73, 1443-1451.

HARJU, A. M. AND NIKKANEN, T. 1996. Reproductive success of orchard and nonorchard pollens during different stages of pollen shedding in a Scots pine seed orchard. Can. J. For. Res., 26, 1096-1102.

HAYASHI, Y. 1952. The natural distribution of important trees, indigenous to Japan. Conifers Report 2: Bull. Gov. Forest Exp. St., Tokyo, 55, 241-242.

ISAGI, Y., KANAZASHI, T., SUZUKI, W., TANAKA, H. AND ABE, T. 2000. Microsatellite analysis of the regeneration process of Magnolia obovata Thunb. Heredity, 84, 143-151.

LATTA, R. G., LINHART, Y. B., FLECK, D. AND ELLIOT, M. 1998. Direct and indirect estimates of seed versus pollen movement within a population of ponderosa pine. Evolution, 52, 61-67.

LEVIN, D. A. AND KERSTER, H. W. 1974. Gene flow in seed plants. Evol. Biol., 7, 139-220.

LIAN, C., MIWA, M. AND HOGETSU, T. 2000. Isolation and characterization of microsatellite loci from the Japanese red pine. Mol. Ecol., 9, 1186-1188.

LINHART, Y. B., BUSBY, W. H., BEACH, J. H. AND FEINSINGER, P. 1987. Forager behavior, pollen dispersal and inbreeding in two species of hummingbird-pollinated plants. Evolution, 41, 679-682.

MitTon, J. B. 1992. The dynamic mating systems of conifers. New Forests, 6, 197-216.

MitTon, J. B., LATTA, R. G. AND ReHFELDT, G. E. 1997. The pattern of inbreeding in Washoe pine and survival of inbred progeny under optimal environmental conditions. Silvae Genet., 46, 215-218.

MORIN, P. A., MOORE, J. J., CHAKRABORTY, R. J. I. N. L., GOODALL, J. AND WOODRUFF, D. S. 1994. Kin selection, social structure, gene flow, and the evolution of flowering time. Science, $\mathbf{2 6 5}$, 1193-1201.

MURAWSKI, D. A. 1995. Reproductive biology and genetics of tropical trees from a canopy perspective. In: Loman, M. and Nadkarni, N. (eds) Forest Canopy, pp. 457-493. Academic Press, New York.

NEI, M. 1987. Molecular Evolutionary Genetics. Columbia University Press, New York.

PERRY, D. J. AND DANCIK, B. P. 1986. Mating system dynamics of lodgepole pine in Alberta, Canada. Silvae Genet., 35, 190-195.

SCHNABEL, A. 1998. Parentage analysis in plants: mating systems, gene flow, and relative fertilities. In: Carvalho, G. R. (ed.) Advances in Molecular Ecology, pp. 173-189. IOS Press, Oxford. 
SChUSTER, W. S. F. AND MitTon, J. B. 2000. Paternity and gene dispersal in limber pine (Pinus flexilis James). Heredity, 84, 348-361.

SHAW, D. V. AND ALLARD, R. W. 1982. Estimation of outcrossing rates in Douglas-fir using isozyme markers. Theor. Appl. Genet., 62, 113-120.

SHAW, D. V., KAHLER, A. L. AND ALLARD, R. w. 1981. A multilocus estimator of mating system parameters in plant populations. Proc. Natl. Acad. Sci. U.S.A., 78, 1298-1302.

SORENSEN, F. C. 1994. Frequency of seedlings from natural selffertilization in Pacific Northwest ponderosa pine (Pinus ponderosa Dougl. ex Laws.). Silvae Genet., 43, 100-108.
STREIFF, R., DUCOUSSO, A., LEXER, C., STEINKELllNER, H., Gloessl, J. AND KREMER, K. 1999. Pollen dispersal inferred from paternity analysis in a mixed oak stand of Quercus robur L. \& Q. petraea (Matt.) Liebl. Mol. Ecol., 8, 831-841.

TAUBER, M. 1977. Investigations of aerial pollen transport in a forested area. Dansk Bot. Arkiv, 32, 1-121.

UENO, S., TOMARU, N., YOSHIMARU, H., MANABE, T. AND YAMAмото, s. 2000. Genetic structure of Camellia japonica L. in an old-growth evergreen forest, Tsushima, Japan. Mol. Ecol., 9, 647-656. 